\title{
A LOGÍSTICA REVERSA COMO ÂNCORA DA SUSTENTABILIDADE E RESPONSABILIDADE SOCIAL
}

\section{REVERSE LOGISTICS AS AN ANCHOR OF SUSTAINABILITY AND SOCIAL RESPONSIBILITY}

\section{Wallace Gomes Moraes,}

Administrador, Especialista em Gestão e Manejo Ambiental na Agroindústria pela Universidade Federal de Lavras, Brasil.

e-mail: moraes.wallace@bol.com.br

Recebido: 10/11/2020 - Aceito: 27/11/2020

\section{Resumo}

Atualmente a gestão das empresas adquiriu em sua prática diversos elementos outrora desconsiderados e promoveu a um plano superior alguns aspectos, principalmente aqueles ligados ao meio ambiente, à sustentabilidade $\mathrm{e}$ responsabilidade social. Esta mudança ocorreu primeiramente motivada pelas diferentes manifestações em favor do meio ambiente e da preservação das condições de vida para as gerações futuras, mas num segundo momento, surgiu porque as organizações viram a necessidade de incorporação de tais práticas ao seu cotidiano como forma de garantirem sua própria sobrevivência. Neste contexto a logística reversa surge como uma das principais ferramentas de implantação do desenvolvimento sustentável, absorvendo todas as tradicionais funções da logística e operando, ainda, o "fluxo reverso" de produtos/ serviços - com origem no consumidor e retornando à cadeia produtiva. Desta forma, o presente trabalho tem como objetivo apresentar a Logística Reversa evidenciando sua importância não só como uma alternativa de agregação de valores às empresas mas também como suporte para ações sustentáveis para o desenvolvimento econômico e para a responsabilidade social. Através de pesquisa bibliográfica buscou-se evidenciar que a logística reversa não se restringe aos "modus operandi" preservacionistas mas também tem relevância em todos os outros elementos que compõem o universo empresarial, resultando em ações integradas e o uso de novas tecnologias e estratégias com viés econômico, social e ambiental.

Palavras- chaves: Logística Reversa; Sustentabilidade; Responsabilidade social.

\section{Abstract}


Currently, the management of companies has acquired in its practice several elements that were previously disregarded and promoted some aspects to a higher level, mainly those related to the environment, sustainability and social responsibility. This change occurred primarily due to the different manifestations in favor of the environment and the preservation of living conditions for future generations, but in a second moment, it came about because organizations saw the need to incorporate such practices into their daily lives as a way to guarantee their survival itself. In this context, reverse logistics emerges as one of the main tools for implementing sustainable development, absorbing all the traditional functions of logistics and also operating the "reverse flow" of products / services - originating from the consumer and returning to the production chain. In this way, the present work aims to present the Reverse Logistics evidencing its importance not only as an alternative of adding values to companies but also as a support for sustainable actions for economic development and social responsibility. Through bibliographic research, we sought to show that reverse logistics is not restricted to preservationist "modus operandi" but also has relevance in all other elements that make up the business universe, resulting in integrated actions and the use of new technologies and strategies with bias economic, social and environmental.

Keywords: Reverse Logistics; Sustainability; Social Responsibility.

\section{Introdução}

A logística reversa surge como uma das principais ferramentas de implantação do desenvolvimento sustentável, absorvendo todas as tradicionais funções da logística e operando, ainda, o "fluxo reverso" de produtos/ serviços - com origem no consumidor e retornando à cadeia produtiva.

Os impactos ambientais causados pelo homem começaram a surgir e impeliram as empresas a buscarem alternativas para um posicionamento mais sustentável e com responsabilidade social, através de investimentos em mecanismos antipoluentes, substituição de matérias primas não renováveis por renováveis, redução de desperdícios, eficiência energética e, também, reaproveitamento de resíduos gerados nos processos produtivos e de comercialização de produtos.

Entretanto a implantação de processos sustentáveis de logística reversa demandam inicialmente uma reestruturação cultural das empresas, buscando o desenvolvimento de iniciativas de produção e/ou consumo sustentável. 
Ocorreram transformações substanciais no processo gerencial, saindo de um modelo estático, outrora restrito aos aumentos de produtividade e da rentabilidade, para um modo de atuação ligado a uma visão ampliada, onde o ambiente e os stakeholders têm papel essencial no desenvolvimento empresarial, apropriando de conceitos mais condizentes com o cenário atual.

Assim sendo, o objetivo deste artigo é evidenciar que neste novo cenário corporativo, a adoção de práticas de logística reversa podem servir de ancora para um posicionamento mais sustentável e com viés social, podem angariar valores e diferenciais que possam consolidar a imagem da empresa no mercado, marcando efetiva presença no segmento onde atuam.

\section{2 .Histórico da Logística}

O conceito de logística, existente desde a década de 40, foi utilizado pelas Forças Armadas norte - americanas. Ele relacionava-se com todo o processo de aquisição e fornecimento de materiais durante a Segunda Guerra Mundial, e foi utilizado por militares americanos para atender a todos os objetivos de combate da época. (CHING, 2010).

A logística permaneceu latente entre as décadas de 50 a 70 . Segundo CHING, (2010), a partir da década de 70, a logística empresarial passou para o estado de semimaturidade, já que os princípios básicos amplamente definidos estavam proporcionando benefícios a empresa. A partir da década de 80,0 desenvolvimento da logística tornou-se revolucionário em virtude de fatores, como explosão da tecnologia da informação, alterações estruturais surgidas nos negócios e na economia dos países emergentes, formação de blocos econômicos e no fenômeno de globalização.

Se tomarmos por base o conceito clássico, POZO (2004), diz que logística é a arte de calcular. Essa definição grega de logística serviu de parâmetro para os militares norte-americanos utilizarem como forma de designar a arte de transporte e distribuição e suprimento das tropas em operações. 
Assim segundo CHING, (2010), após 1990, a logística passou a ser entendida como a junção da administração de materiais com a distribuição física. Isto leva a crer que futuramente a produção e a logística se aproximarão cada vez mais não só em conceito, mas também em prática.

\subsection{Logistica Reversa}

A logística reversa vem ganhando expansão no mercado e evoluindo com novas tecnologias e estratégias visando obter vantagens competitivas para as empresas, contribuindo paralelamente para 0 desenvolvimento sustentável e econômico.

As preocupações ambientais são crescentes, necessárias e todos os segmentos do mercado devem se adaptar, notadamente entendendo que a Logistica Reversa pode ser uma alternativa para agregar valores às empresas, produtos e serviços além de trazer conceitos que contribuam para o meio ambiente, através de ações sustentáveis, para o desenvolvimento econômico e para a responsabilidade social.

Segundo MOURA (2006), pode-se dizer que a logística é o processo de gestão dos fluxos de produtos, de serviços e da informação associada, entre fornecedores e clientes ( finais ou intermediários ) ou vice versa, levando aos clientes, onde quer que estejam, os produtos e serviços de que necessitam, em melhores condições.

Dentro das diversas tipologias de logística, surge o conceito de logística reversa que segundo o Council of Logistics Management (CLM) assim definiu:

A logística reversa é definida como a parte do processo da cadeia de suprimento que planeja, implementa e controla de modo eficiente e eficaz o fluxo direto e reverso e o estoque de bens, serviço e informação entre o ponto de origem e o ponto de consumo com 0 propósito de atender os requisitos dos clientes.

De acordo Reverse Logistics Executive Council (2004), a logística reversa é definida como o "processo do planejamento, implementação e controle da eficiência e custo do fluxo de matérias primas, estoques em 
processo, produtos acabados e as informações correlacionadas do ponto do consumo ao ponto de origem."

Lacerda (2000) define :

\begin{abstract}
Logística reversa como sendo o processo de planejamento, implementação e controle do fluxo de matérias primas, estoque em processo e produtos acabados (e seu fluxo de informação) do ponto de consumo até o ponto de origem, com o objetivo de recapturar valor ou realizar um descarte adequado.
\end{abstract}

Garcia (2006, p. 4) define a logística reversa como um processo de: "planejamento, implementação e controle do fluxo de produtos acabados e as respectivas informações, desde o ponto de consumo até o ponto de origem, com o propósito de recapturar valor ou adequar o seu destino". Entende-se, portanto, a logística reversa como todo o processo logístico bem como os controles e planejamentos para produtos que estão vendidos.

O processo logístico direto, o percurso se dá através da entrada da matéria-prima, a cadeia de suprimentos, produção dos produtos e por fim, a distribuição. Já na logística reversa, o processo se inicia após o material pósvenda e/ou pós-consumo, utilizando materiais reaproveitados ou reciclados, ou seja, de forma inversa.

Novaes (2007) aponta a logística reversa como fluxo de materiais do ponto de consumo até o ponto de origem.

A logística reversa dentro da logística empresarial é composta por dois componentes: a movimentação física, inclusive o transporte dos materiais; e a gestão de estoque, incluindo o armazenamento (PIRES, 2009).

Fonseca e Souza (2008) aponta que a Logística reversa é uma continuidade da cadeia de suprimentos que lida com os processos logísticos de produtos que já foram vendidos. Observando que o ciclo do processo logístico se encerra com a entrega do produto ao consumidor final.

Na Figura 01 é possível compreender o processo logístico reverso através do esquema: 
FIGURA 01 - Processo Logístico Reverso

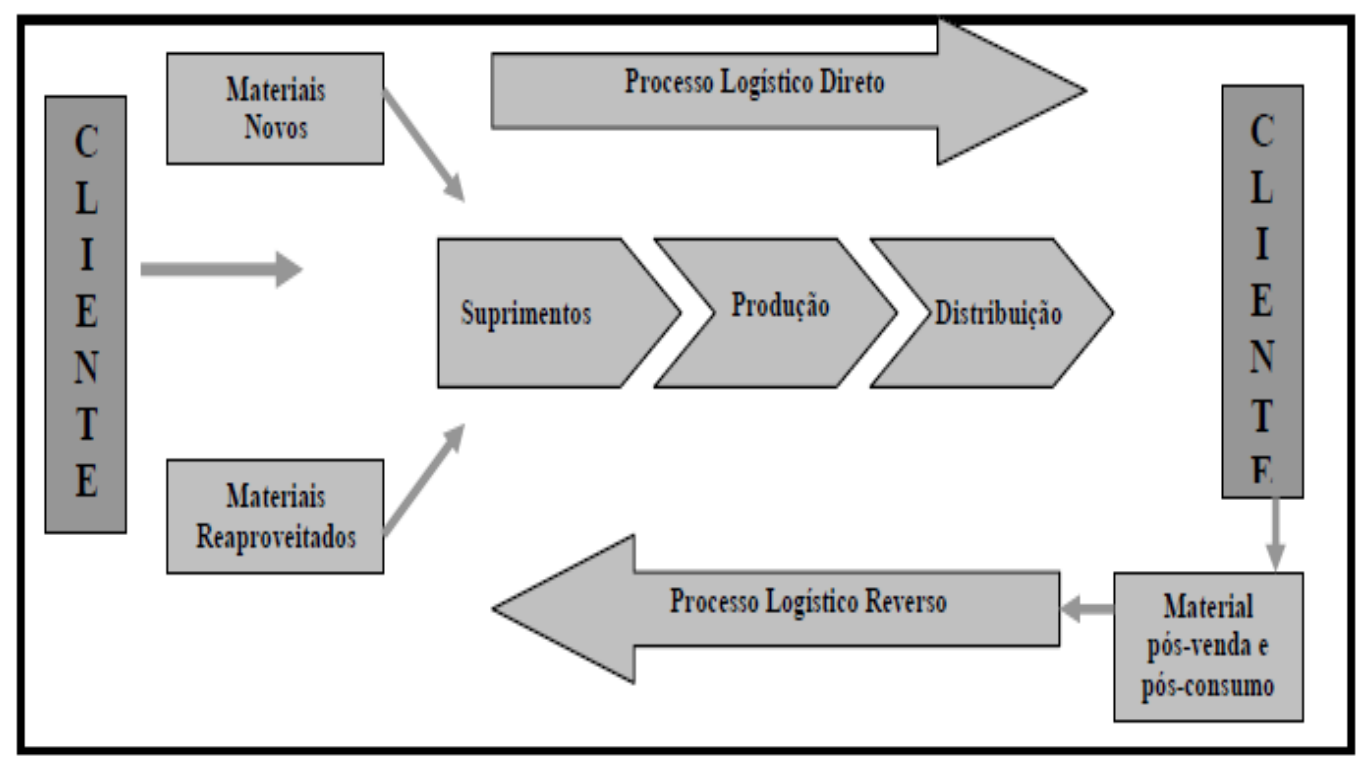

Fonte: (HATAKEYAMA, 2005, p.4)

A importância deste posicionamento por parte das empresas fez com que surgisse legislação tratando a respeito. A logística reversa é um instrumento instituído pela Política Nacional de Resíduos Sólidos - PNRS, e se destaca como um dos meios mais determinantes para garantir o descarte correto e a reciclagem de resíduos.

A lei ambiental sobre a obrigação da logística reversa vigora desde 2010, porém somente em 2017 foi regulamentada através do decreto ํo 9177 . A lei 12.305/2010 regulamenta o manejo adequado dos resíduos e estipula outros dois instrumentos para viabilizar a logística reversa: o termo de compromisso e o acordo setorial.

Segundo a Lei 12.305/10 a logística reversa é o:

Instrumento de desenvolvimento econômico e social caracterizado por um conjunto de ações, procedimentos e meios destinados a viabilizar a coleta e a restituição dos resíduos sólidos ao setor empresarial, para reaproveitamento, em seu ciclo ou em outros ciclos produtivos, ou outra destinação final ambientalmente adequada.

O intuito da lei ambiental é instituir instrumentos para a gestão de resíduos, permitindo que o país enfrente os principais problemas ambientais, 
sociais e econômicos causados pelo manejo incorreto dos resíduos. Além disso, pode ser uma oportunidade de negócio a logística reversa de produtos comercializados em embalagens plásticas, metálicas ou de vidro.

Esse processo divide a responsabilidade de adequação de resíduos com o consumidor e o estado, de forma a encontrar formas de destinação correta para os resíduos. Nesse contexto, todos têm a responsabilidade de participar da devolução, reciclagem e destinação ambiental apropriada de determinados produtos.

A logística reversa viabiliza a economia nos processos produtivos das companhias, já que os resíduos retornam à cadeia produtiva, o que diminui o consumo e os custos de matérias-primas. Esse processo de retorno de resíduos às empresas de origem evita que eles possam poluir ou contaminar o ambiente.

Configura-se aí a importância das empresas adotarem práticas para assumir o retorno de seus produtos descartados, viabilizando sua destinação apropriada ao fim de seu ciclo de vida útil. Este processo de gerenciamento dos produtos após o fim do seu ciclo de vida tem como objetivo maior neutralizar o impacto ambiental que estes resíduos podem provocar se forem descartados incorretamente.

A logística reversa portanto ,consiste em um processo que planeja, opera e controla o fluxo e as informações logísticas referentes ao retorno dos materiais após o consumo para as empresas fabricantes de tal produto, devendo ser, por força de lei, ser cumprida por fabricantes, importadores, distribuidores ou comerciantes.

Assim, o conceito central da logística reversa pode ser entendido como o processo de movimentar produtos de suas destinações típicas para outros pontos. O propósito é de capturar valores não disponíveis de outro modo ou para disposição adequada de produtos. Esta definição abrange, ainda, diversas atividades como: processamentos de retornos por danos, sazonalidades, recall, excesso de estoques, etc.; reciclagem; recondicionamento; remanufatura; dentre outros. 
A logística reversa pode acontecer no pós consumo e no pós venda. Quando isso acontece no pós consumo, existe a possibilidade de revalorização dos produtos, dependendo evidentemente da destinação final. De igual forma, a logística reversa de pós venda pode também buscar a revalorização dos produtos, através de várias destinações. A logística reversa de pós venda é parte integrante do nível de serviço da imagem da empresa e do produto, sendo pois uma continuidade do relacionamento com o cliente, podendo se transformar em uma vantagem competitiva.

Por outro lado, Moraes (2019) enfatiza que deve-se considerar que o processo reverso subtrai resultado do fluxo normal, é um retrabalho e, portanto, incorre em custos. Por isso mesmo, é fundamental conhecer os motivos que ocasionaram a devolução dos produtos, para eliminar os motivos do processo reverso.

No quadro a seguir, exemplifica a situação:

\section{MOTIVAÇÃO DO RETORNO}

Fim da utilidade pelo consumidor primário Salvados (seguros, leilões)

Fim da vida útil

Resíduos Industriais

Aterro Sanitário e/ou Incineração

\section{DESTINAÇÃO DOS PRODUTOS}

Mercado Secundário

Remanufatura

Desmanche

Reciclagem

\subsection{Vantagens da Logistica Reversa}

A logística reversa, apesar de associada principalmente ao conceito de sustentabilidade, apresenta benefícios importantes ao empreendimento além dos benefícios ao meio ambiente, já que oferece vantagens à marca e à relação dela com o consumidor, criando uma imagem sólida e positiva perante os clientes, propiciando a exploração de ações vinculadas de marketing, melhoria no processo de produção gerando produtos mais eficientes e a criação de consumidores mais conscientes.

Dentro desta ótica, segundo Moraes (2019) os desafios dos gestores serão ditados pelas exigências dos consumidores, pelas normas ambientais e 
por pressões da sociedade objetivando a conformidade com a legislação ambiental, aprimoramento da imagem corporativa, minimizar os riscos de passivos ambientais, utilização de tecnologias mais eficientes de produção e melhorar a aceitação dos produtos.

Essa sensibilidade ecológica atrelada à logística reversa pode se transformar em vantagem competitiva e financeira para as empresas à medida que elas irão receber menos reclamações relacionadas à devolução de produtos, criam novas oportunidades e nichos de mercado além de melhorar e gerar uma imagem positiva diante do mercado, dos clientes e da sociedade em geral, sofrem menos processos judiciais, em função das novas legislações ambientais, evitando assim multas pesadas e até interdição. Este comportamento evidentemente faz com que as empresas se destaquem de suas concorrentes com uma boa imagem perante a sociedade além do retorno econômico.

Um programa de logística reversa instituído em uma empresa traz diversos benefícios, principalmente os associados à sustentabilidade. Entre esses benefícios temos a redução da quantidade de resíduo a ser descartado, diminuição dos custos com matéria prima já que os resíduos que retornam podem ser reaproveitados no processo de fabricação, proporciona à marca criar uma identidade ecologicamente correta e promove a consciência sustentável.

A implantação da logística reversa e o aumento da conscientização são determinantes para reduzir os impactos negativos ocasionados pelo descarte incorreto dos resíduos, o que melhora a qualidade de vida dos cidadãos urbanos e as atividades da marca como um todo.

\section{3- Sustentabilidade}

A sustentabilidade pode ser considerada como um conceito relativamente novo, de abrangência e influência extremamente disseminadas em todos os meios, desde os espaços familiares de convivência até o meio corporativo, onde inclusive tem reflexos na competitividade das empresas. 
O primeiro passo para a construção de um conceito abrangente acerca da sustentabilidade ocorreu com a Conferência de Estocolmo, em 1972. No entanto, uma visão sintética a respeito do assunto somente foi trazida a baila, à partir do relatório Nosso Futuro Comum, publicado pela Comissão Mundial para o Meio Ambiente e o Desenvolvimento em 1987, que afirma que o "desenvolvimento sustentável é aquele que busca as necessidades presentes sem comprometer a capacidade das gerações futuras de atender suas próprias necessidades".

Afonso (2006) aponta que nesse relatório a ideia de sustentabilidade vem como um processo de transformação, onde a exploração e extração dos recursos naturais para o desenvolvimento tecnológico seja harmonioso com as gerações presentes e futuras, atendendo as necessidades humanas

Para Boff (2012), a sustentabilidade pode ser observada como toda ação voltada à manutenção das condições energéticas, físico-químicas e informacionais que sustentam os seres de modo geral. Essa ótica, de caráter holístico, indica uma superação do antropocentrismo até então vigente, convergindo para uma visão ampla e confere a todos os elementos, bióticos e abióticos, importância na construção, melhoria e manutenção da qualidade de vida.

Para Layrargues (1997), a questão ambiental só ganhou força quando se apresentava como um grave problema no meio produtivo, e só então se iniciou a discussão acerca de ecoeficiência e do que seria politicamente correto.

$\mathrm{Na}$ atualidade é imprescindível a busca pelo desenvolvimento econômico e o desenvolvimento sustentável. Entretanto, o debate sobre sustentabilidade somente ganhou ênfase a partir da conclusão de que os déficits ora identificados no tocante ao meio-ambiente e qualidade de vida passaram a ter influência direta nas questões internas das empresas.

Nesse contexto, os stakeholders passaram a ser objeto de preocupação por parte das organizações e dos estudiosos do assunto, notadamente quando relacionados à prática gerencial. Assim, a sustentabilidade passou a fazer parte 
do conjunto de elementos que compõem a gestão empresarial, confirmando-se como objeto de estudo e de necessária apropriação por parte dos profissionais.

A sustentabilidade, no universo dos conceitos e práticas ora preconizados no meio corporativo, ocupa espaço privilegiado nos debates e decisões gerenciais em todos os segmentos.

A difusão atual destes conceitos reflete a necessidade identificada após décadas de descaso com a questão, especialmente considerando o desenvolvimento adquirido pelos meios de produção, que não teve um acompanhamento efetivo no tocante às políticas sustentáveis no âmbito do cuidado com o meio ambiente, resultando em prejuízos não mais reparáveis em sua completude.

A Agência Estado/Meio Ambiente conceitua desenvolvimento sustentável como Modelo de desenvolvimento que leva em consideração, além dos fatores econômicos, aqueles de caráter social e ecológico, de modo equilibrado. A partir da constatação, de que os recursos naturais têm uma oferta limitada, isto é, podem acabar, defende a idéia de sua reposição permanente através do uso adequado, isto é, ecologicamente equilibrado, dentro de práticas econômicas eficientes. ( Câmara, 2002)

O desenvolvimento sustentável, segundo a Comissão mundial sobre meio ambiente e desenvolvimento (CMMAD) é um processo de transformação, no qual a exploração dos recursos, a direção dos investimentos, a orientação da evolução tecnológica e a mudança institucional se harmonizam e reforçam o potencial presente e futuro, a fim de atender às necessidades e aspirações humanas.

Desta forma as primeiras iniciativas na definição de soluções para o problema dos impactos ambientais causados pelo homem começaram a surgir e impeliram as empresas a buscar alternativas para a produção sustentável, através de investimentos em mecanismos antipoluentes, substituição de matérias primas não renováveis por renováveis, redução de desperdícios, eficiência energética e, também, reaproveitamento de resíduos gerados nos processos produtivos e de comercialização dos produtos. 
Segundo GUARNIERI (2011), inserir a discussão da sustentabilidade no ambiente de negócios tornou-se uma prática constante para empresas preocupadas com sua imagem corporativa e com a manutenção dos clientes.

Tanto assim que MORAES (2012), define a manutenção da qualidade do ar, da água, do solo, da vida das plantas e animais, enfim, do ambiente natural que dá suporte à vida no planeta, um valor para nossa sociedade. Por isto temos o meio ambiente como nosso maior bem comum e a sua preservação como uma responsabilidade coletiva.

Para GUARNIERI ( 2011), a visão sustentável no ambiente de negócios insere uma nova realidade, na qual é necessário reconsiderar a utilização dos recursos naturais e os interesses da comunidade, e extrair vantagens competitivas desta situação, através da utilização de tecnologias mais efetivas em prol da sustentabilidade.

Pode-se dizer que esse conceito de sustentabilidade representa promover a exploração de áreas ou o uso de recursos naturais ou não, de forma a prejudicar o menos possível o equilíbrio entre o meio ambiente e as comunidades humanas e toda a biosfera que dele dependem para existir. Diante desta configuração pode parecer um conceito difícil de ser implementado e, em muitos casos, economicamente inviável. (Moraes,2012)

Uma empresa votada para as questões ambientais estará se antecipando às auditorias ambientais públicas além de promover a redução de custos e riscos com a melhoria de processos e a racionalização de consumo de matérias primas; diminuição do consumo de energia e água e redução de riscos de multas e responsabilização por danos ambientais. A idéia embutida nos conceitos dos 4 R's (rever, reciclar, reduzir e reutilizar) fica cada dia mais em pauta e valorizada no ambiente corporativo. (Moraes,2012).

Portanto, de acordo com MORAES (2012), já foi o tempo em que as questões ambientais eram tratadas sob a ótica do idealismo e do romantismo. Hoje, as questões ambientais fazem parte do contexto empresarial, visto que as empresas pressionadas por leis ambientais, pela sociedade e pelo mercado são levadas a implementarem ações que garantam a sua sustentabilidade. 
Assim, dentro deste contexto vislumbra-se a importância de um programa de gestão ambiental voltado para o trinômio maior da sustentabilidade e responsabilidade social qual seja uma empresa economicamente viável, socialmente justa e ecologicamente sustentável. (Moraes,2012)

\subsection{Logística reversa e sustentabilidade}

Na perspectiva sustentável existem as dimensões social, econômica e a proteção ambiental, na abordagem do chamado Tripé da Sustentabilidade. 0 Tripé da Sustentabilidade diz respeito à atuação das organizações com base no social, ambiental e financeiro, abordando um desenvolvimento sustentável, onde não haja um aspecto sobrepondo à outra. As organizações devem atuar buscando equilibrar e harmonizar os três aspectos, não visando apenas a obtenção de lucros, mas também o meio ambiente e as ações sociais, conforme representado na Figura 02:

FIGURA 02 - Tripé da Sustentabilidade 


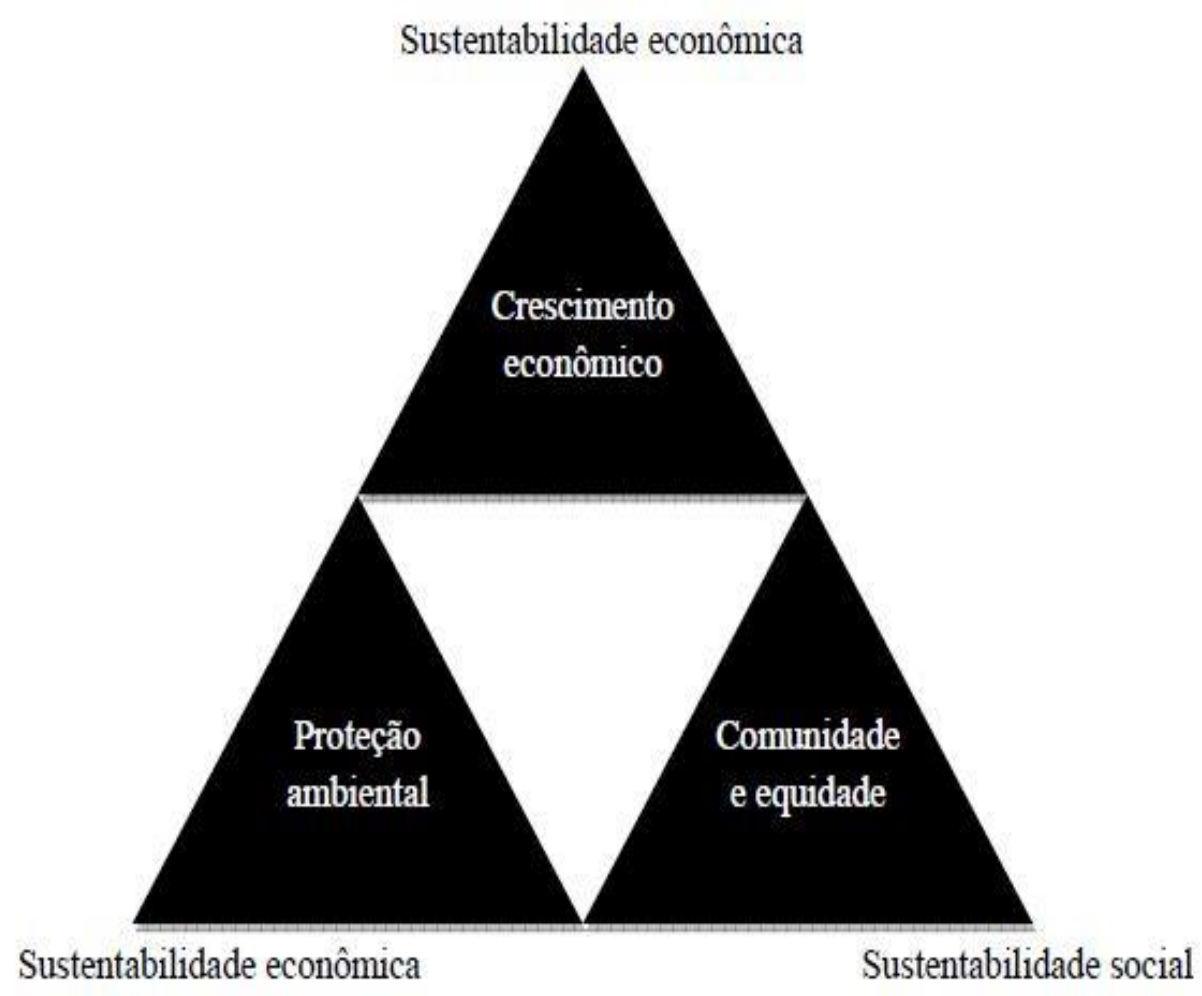

FONTE: (ISIDRO, 2013, p. 23)

Venturini e Lopes (2014) definem que o Tripé da Sustentabilidade: "compreende os aspectos econômicos, social e ambiental, ganhou reconhecimento considerável, sendo componente das estratégias das empresas na inovação e na geração de valor". Desta forma representa a harmonização entre os aspectos sociais, ambientais e financeiros.

A logística reversa está inserida no ambiente empresarial e está intimamente ligada à sustentabilidade. Guarnieri (2011) descreve que:

A logística reversa é justamente a estratégia que cumpre o papel de operacionalizar o retorno dos resíduos de pós-venda e pós-consumo ao ambiente de negócios e/ou produtivo, considerando que somente dispor de resíduos em aterros sanitários, controlados ou lixões não basta no atual contexto empresarial.

Guarnieri (2011) aponta que a logística reversa apoia-se na sustentabilidade ambiental e econômica, reafirmando a possibilidade de 0 
desenvolvimento econômico percorrer juntamente como o desenvolvimento ambiental e sustentável.

Assim, depara-se com duas vertentes da logística reversa associada à sustentabilidade: a logística verde ou logística ecológica e a cadeia da demanda, onde há o envolvimento de todos os processos logísticos (PEREIRA, 2012).

A logística reversa pode se apresentar como estratégia para obter vantagens competitivas. Alguns fatores contribuem para que a logística reversa atribua e agregue valor a empresa.

Guarnieri (2011) aponta que um dos fatores diz respeito às questões ambientais, contribuindo de maneira efetiva na manutenção da sustentabilidade nos negócios, sendo planejada de forma que torne possível o retorno dos resíduos produzidos, além destas empresas estarem agindo de acordo a Lei.

Outro fator que a logística reversa possibilita é quanto a redução de custo. Guarnieri (2011) aborda que há uma redução de custo com o processo de reciclagem e reutilização, como o de embalagens. Chaves e Batalha (2006) elucidam ainda para a adoção de utilização de embalagens retornáveis.

Buscando ainda aumentar o nível da competitividade empresarial Silva e Colmenero (2010) apontam a fidelização dos clientes, no atendimento e substituição de produtos com algum tipo de defeito ou avaria.

Chaves e Batalha (2006) apontam ainda para a inserção de políticas liberais para retorno e troca de produtos, eliminando os processos com entraves e processos burocráticos demorados, que acabam dificultando o relacionamento do cliente com o fornecedor, assim como a satisfação do consumidor.

A imagem corporativa é crucial para qualquer empresa, portanto é necessário primar para a diferenciação e destaque desta imagem. Silva e Colmenero (2010, p. 5) apontam "a preocupação com o retorno dos produtos, pós-venda e/ou pós-consumo, aliada a utilização do marketing ambiental, proporciona a visualização de uma empresa ecologicamente correta". Atribuindo ainda, uma imagem corporativa diferenciada. 
Isidro (2013) aposta no posicionamento como empresa cidadã na diferenciação da imagem corporativa,atribuindo assim valores quanto aos aspectos ambientais e responsabilidade social para a imagem institucional.

Braga Junior (2007) afirma que a preocupação das empresas com à comunidade onde está inserida é também um fator de diferenciação da imagem corporativa, destacando ainda a participação em projetos sociais.

Leite (2005) atribui ainda a chamada sensibilidade ecológica onde há uma preocupação com a disposição final do lixo urbano, através do gerenciamento de impactos ambientais.

\subsection{Responsabilidade Social}

A responsabilidade social empresarial nada mais é do que um conjunto de ações e iniciativas tomadas pelas empresas buscando, de maneira completamente voluntária, contribuir com questões de ética, meio ambiente e a sociedade.

Tanto assim que a responsabilidade social torna-se indispensável no contexto onde as decisões estratégicas de grandes empresas envolvem tanto consequências econômicas quanto sociais, já que estas estão necessariamente interligadas (MINTZBERG, 1983).

Contitui-se em uma política que guia todos os passos da empresa, de forma a torná-la mais ética, responsável, sustentável e humana, influenciando na condução do negócio e como a empresa lida com os parceiros, colaboradores e clientes. É uma forma que as empresas têm de transmitir um desejo de todo ser humano: causar um impacto positivo no mundo.

A responsabilidade social empresarial funciona como um plano de negócios paralelo, que atua em conjunto com o plano de negócios real, pois tem seus próprios objetivos e metas definidos. A ideia principal é gerar valor para todos os envolvidos na empresa, o que inclui clientes, colaboradores e parceiros de negócio, podendo se estender para a sociedade como um todo, a depender: 
Além de unir colaboradores que desejam ter um propósito no seu trabalho, atrai clientes que querem sentir que estão fazendo parte de algo maior ao consumirem produtos ou serviços da empresa e, por consequência, se tornam fiéis à marca.

Segundo Ferrel, Fraedrich e Ferrel (2000), a empresa tem a obrigação de restituir a sociedade pelos benefícios dela recebidos. Conforme os autores, a empresa deve ter como objetivo maximizar os efeitos positivos enquanto minimiza os efeitos negativos causados na sociedade.

Assim, especialmente considerando a responsabilidade social ambiental e o crescente clamor social pela preservação da natureza e dos recursos naturais como um todo, as empresas necessitam de metodologias e práticas que as integrem a essa realidade que ora o mercado apresenta.

As indústrias, principalmente, que causam danos ao meio ambiente devem ter essa preocupação tanto pautando-se pelo bom senso quanto motivadas pela competitividade a ela relacionada.

Conforme ZILBERSZTAJN E NEVES (2000), a globalização e a expansão das indústrias tornaram necessária a adaptação ao fator ambiental objetivando uma menor agressão possível ao ambiente, exigindo dos gestores atuais uma observação diferente acerca do trabalho e, por conseguinte, o surgimento de uma nova forma de administração, que é a administração ambiental e a análise de seus impactos, com a consequente propositura de solução para sua minimização.

Cabe às empresas incentivarem a interrelação através de políticas abrangentes e que extrapolem os limites das áreas de interesse da empresa, com a expansão aos níveis de influência na comunidade, confirmando Carvalhosa (1977), que afirma que a empresa tem uma óbvia função social, nela sendo interessados os empregados, os fornecedores e a comunidade em que atua e o próprio Estado, que dela retira contribuições formadas pelos tributos e impostos.

A responsabilidade social passou a ter uma relação estreita com a competitividade, após um relativo nivelamento produtivo ligado a fatores como localização geográfica das empresas, acesso a tecnologias e matérias-primas 
e outros requisitos. Esta relação, no entanto, tem como obstáculo os interesses conflitantes existentes entre capital e trabalho e a dificuldade de integração entre as partes, principalmente quando está em questão o lucro, elemento essencial objetivado pela produção.

As políticas de responsabilidade social devem necessariamente, conforme Coutinho e Macedo-Soares (2002), estar alinhadas à estratégia de negócios da organização que as irá promover.

A estratégia em questão pode ser entendida como um padrão de decisões que determina propósitos, objetivos, metas, políticas e planos a serem obtidos (ANDREWS, 2007).

As estratégias de responsabilidade social empresarial foram exploradas ainda por Husted \& Salazar (2006), os quais desenvolveram um estudo que examinou empresas cujo objetivo era a maximização do lucro e do desempenho social. Concluíram os autores através do estudo que as empresas podem agregar valor e obter vantagens competitivas por intermédio de sua atuação socialmente responsável, mas devem atuar estrategicamente, e a responsabilidade social empresarial deve estar vinculada à estratégia empresarial.

Husted \& Allen (2001) destacam que as estratégias de responsabilidade social empresarial podem gerar vantagens competitivas se utilizadas de maneira adequada pelas empresas, afirmando que existe uma relação positiva entre as ações de responsabilidade social estratégica e a geração de vantagens competitivas.

A reputação perante a sociedade é um poderoso conceito para os negócios, governos e organizações sem fins lucrativos, já que executivos, administradores e stakeholders internos e externos constantemente a utilizam para avaliar e comunicar suas percepções dos negócios e empresas (LOGSDON E WOOD, 2002).

$\mathrm{Na}$ atualidade, são diversas as posturas no âmbito corporativo que traduzem a ideia da responsabilidade social e estas há muito deixaram de pertencer ao campo do diferencial empresarial de competitividade para adentrar a questão da necessidade para sobrevida das organizações. 
Para Ashley (2002), a "responsabilidade social pode ser definida como o compromisso que uma organização deve ter para com a sociedade, expresso por meio de atos e atitudes que a afetem positivamente".

De acordo com Megginson et al. (1998), a "responsabilidade social representa a obrigação da administração de estabelecer diretrizes, tomar decisões e seguir rumos de ação que são importantes em termos de valores e objetivos da sociedade". Assim, pode-se compreender que a mesma se aproxima da ética corporativa que, para Matos (2012), "é a maneira de 'ser' de uma organização. Significa que sua conduta pública se orienta por princípios de valor consensuais, que caracterizam um perfil próprio".

A responsabilidade social empresarial traduz-se como uma obrigação da empresa de maximizar seus impactos positivos sobre os stakeholders, que são compreendidos como sendo os clientes, propriedade, empregados, comunidade, fornecedores e governo, minimizando seu passivo negativo (FERREL, 2001).

Para Ferrel (2001), no Brasil, a ideia de responsabilidade social conquistou maior espaço na década de 1980 e sedimentou-se no conjunto de ações das empresas principalmente entre 1990 e 2003. A responsabilidade social pode ser legal, ética, econômica e filantrópica, a saber: filantrópica: restituição à sociedade, econômica: maximizar a riqueza para os stakeholders, ética: seguir os padrões de conduta devidos e legal: cumprir o regulamento legal vigente.

\section{3- Metodologia}

A metodologia do presente trabalho é a pesquisa bibliográfica, que, conforme Diehll e Tatim (2004), desenvolve-se a partir de material já elaborado, constituído principalmente de livros e artigos científicos.

A Pesquisa Bibliográfica abrange bibliografia já tornada pública em relação ao tema de estudo, desde publicações avulsas, boletins, jornais, revistas, livros, pesquisas monografias, teses..., até meios de comunicação orais: rádio, gravações em fita magnética e audiovisuais: filmes e televisão. 
Sua finalidade é colocar o pesquisador em contato direto com tudo o que foi escrito, dito ou filmado sobre determinado assunto.

Segundo (Lakatos,2003) "Dessa forma, a pesquisa bibliográfica não é mera repetição do que já foi dito ou escrito sobre certo assunto, mas propicia o exame de um tema sob novo enfoque ou abordagem, chegando a inovações inovadoras."

Para Gil (2002), inúmeras são as colaborações da pesquisa bibliográfica para pesquisador e pesquisado:

Desta forma, este trabalho conta com uma pesquisa bibliográfica, pois se baseia na busca de autores que já discorrem sobre o tema, realizando a compilação das ideias, comparando ou refutando-as.

\section{Considerações Finais}

$\mathrm{Na}$ atualidade competitividade entre as empresas e organizações está mais acirrada. É cada vez mais crescente a busca das empresas por estratégias que possam servir como alavanca de um diferencial competitivo.

A exigência do mundo globalizado não diz respeito apenas à obtenção de lucros e rentabilidade, mas também que vise o desenvolvimento sustentável. Neste contexto e diante das exigências de questões ambientais e a sustentabilidade, no âmbito corporativo, destaca-se a logística reversa.

Ela constitui-se em uma ferramenta imprescindível para as empresas que desejam tornar-se ambientalmente responsáveis, através do gerenciamento eficaz e eficiente de seus resíduos gerados. Pressões constantes do mercado, da legislação, dos clientes, faz surgir necessidades e mudanças se fazem necessárias.

Diante deste cenário a logística reversa constitui-se em uma alternativa para agregar valor para a empresa, por meio da adoção de estratégias como a preocupação com as questões ambientais, a redução de custo, aumentar 0 nível da competitividade empresarial, a diferenciação na imagem corporativa, a 
elevação no nível do serviço oferecido ao consumidor/cliente e a sensibilidade ecológica.

Todas estas questões estão inseridas dentro do conceito de logística reversa, possibilitando que as empresas e organizações agreguem valor ao serviço prestado e ao produto oferecido, além de contribuir para o meio ambiente, através de ações sustentáveis, para o desenvolvimento econômico e para a responsabilidade social.

A práxis outrora predominante, com as empresas tendo suas atividades direcionadas única e exclusivamente para a obtenção de lucros, numa visão imediatista e fechada, deram lugar a posicionamentos que levem em consideração questões relacionadas com 0 meio ambiente e a responsabilidade social.

A visão retrógada antes predominante no mundo corporativo cede lugar, de forma gradativa, à consideração de que deve existir a mútua contribuição entre as organizações e a sociedade de modo geral, onde cada parte contribui à sua maneira para a melhoria tanto da qualidade de vida dos cidadãos quanto para a competitividade e viabilidade empresarial, de forma sustentável.

Para esse novo paradigma faz-se necessário que as empresas implementem processos sustentáveis de desenvolvimento, através de uma reestruturação cultural com o envolvimento e comprometimento de toda a cadeia de suprimentos, pois uma das principais dificuldades no gerenciamento destes processos é a diferença, o desencontro, entre os objetivos dos fabricantes, distribuidores, varejistas e consumidores de forma geral.

O fato é que atualmente o mercado está se tornando cada vez mais competitivo e as empresas precisam entender as necessidades do cliente com a criação de valor, além de transmitir uma imagem positiva para a sociedade no tocante a questões ambientais e de responsabilidade social, pois sua perenidade está condicionada a este posicionamento.

Portanto, é possível obter um equilíbrio entre o desenvolvimento econômico, desenvolvimento sustentável e o social, tendo a logística reversa como uma alternativa e base para o alcance do grande desafio das empresas 
atualmente, qual seja, de ser economicamente viável, ecologicamente sustentável e socialmente justa.

\section{Referências}

AFONSO, Cintia Maria. Sustentabilidade: caminho ou utopia? São Paulo: Annablume, 2006.

ASHLEY, Patrícia Almeida et al. Ética e Responsabilidade Social nos negócios. São Paulo: Saraiva, 2002.

BOFF, Leonardo. Sustentabilidade: o que é: o que não é. Petrópolis: Vozes, 2017.

BOURSCHEIDT, D. M.; DALCOMUNI, Sonia Maria. Do crescimento econômico ao desenvolvimento sustentável: Aspectos Conceituais e Marcos Importantes. Revista Congrega Urcamp, v. 4, p. 42-58, 2010.

BRITO, Francisco e Câmara,João. Democratização e Gestão Ambiental: Em busca do desenvolvimento sustentável. 3ed. Petrópolis: Atlas,2002.

CARVALHO, Isabel. "O 'ambiental' como valor substantivo e atributo identitário da educação ambiental". In SAUVÉ, L. EDAMAZ. Montreal: Projeto EDAMAZ, 2001.

CARVALHOSA, Modesto. Comentários à lei de sociedades anônimas. São Paulo: Saraiva, 1977. v. 3.

CHING, Hong Yuh. Gestão de Estoque na Cadeia de Logística Integrada Supply Chain. $3^{\circ}$ ed. $-2^{\circ}$ reimpressão - São Paulo: Editora Atlas S.A,2006 COUTINHO, Renata Buarque G. \& MACEDO-SOARES, T. Diana L. v. A. 
Gestão estratégica com responsabilidade social: arcabouço analítico para auxiliar sua implementação em empresas no Brasil. Revista de Administração Contemporânea - RAC, v. 6, n. 3, p. 75-96, setembro-dezembro, 2002.

DIEHLL, ASTOR. TATIM, DENISE. Pesquisa em ciências sociais aplicadas: métodos e técnicas. São Paulo. Pearson Prentice Hall, 2004. FERREL, O. C.; FRAEDRICH, John; FERREL, Linda. Ética Empresarial: dilemas, tomadas de decisões e casos. Rio de Janeiro: Reichmann \& Affonso, 2001.

FONSECA, S.U.L.; SOUZA, S.F. - Logística reversa: Oportunidades para redução de custos em decorrência da evolução do fator ecológico. SEMEAD, 2008.

GARCIA, Manuel Garcia. Logística reversa: uma alternativa para reduzir custos e criar valor. XIII SIMPEP 2006.

GIL, A. C. Como elaborar projetos de pesquisa. São Paulo: Atlas, 2002. GUANIERI, Patricia, Logística Reversa: em busca do equilíbrio econômico e ambiental, $1^{\circ}$ ed.-Recife, 2011.

HATAKEYAMA, KazUo. Como a logística reversa pode agregar valor econômico, legal e ecológico às empresas: Estudo de caso em uma madeireira. UNAERP, 2005.

LACERDA, Leonardo. Logística reversa: uma visão sobre os conceitos básicos e as práticas operacionais. São Paulo. 2002.

LAKATOS, Eva Maria. Metodologia Cientifica - 5. Ed. - São Paulo: Atlas, 2009. 
LAYRARGUES, P. P. Do ecodesenvolvimento ao desenvolvimento sustentável: evolução de um conceito. Rio de Janeiro: Zahar Editores, 1997.

LEITE, Paulo Roberto. Logística reversa: meio ambiente e competitividade. São Paulo: Pearson Prentice Hall, 2005.

MEGGINSON, Leon, C. Et al. Administração: conceitos e aplicações. São Paulo: Harbra, 1998.

MORAES, Wallace Gomes, Dilemas do Administrador, Ed. Ixtlan, São Paulo,2012

Administração de Recursos Materiais e Patrimoniais : Um enfoque pratico, Ed. Ixtlan, São Paulo, 2019.

MOURA, Benjamim do Carmo, Logística: Conceitos e Tendências, $1^{\circ} \mathrm{Ed}$, 2006.

NOVAES, Antonio Galvão. Logística e gerenciamento da cadeia de distribuição. Rio de Janeiro: Elsevier, 2007.

PEREIRA, André Luiz. Logística reversa e sustentabilidade. São Paulo: Cengage Learning, 2012.

POZO, H. Administração de recursos materiais e patrimoniais: uma abordagem logística: $3^{a}$ ed. São Paulo: Atlas, 2004.

TAKESHY, Tachizawa. Gestão Ambiental e responsabilidade social corporativa. São Paulo: Atlas, 2004.

VENTURINI, Lauren Dal Bem. LOPES, Luis Felipe Dias. O modelo Triple Bottom Line e a sustentabilidade na administração pública: pequenas 
Revista Multidisciplinar do Nordeste Mineiro, 2020/02 ISSN 2178-6925

práticas que fazem a diferença. Repositório da Universidade Federal de Santa Maria - UFSM, 2015. 